\title{
Aich Recombinant human acid $\alpha$-glucosidase Major clinical benefits in infantile-onset Pompe disease
}

\author{
P.S. Kishnani, MD*; D. Corzo, MD*; M. Nicolino, MD, PhD; B. Byrne, MD, PhD; H. Mandel, MD; \\ W.L. Hwu, MD, PhD; N. Leslie, MD; J. Levine, MD; C. Spencer, MD; M. McDonald, MD; J. Li, MD; \\ J. Dumontier, MD; M. Halberthal, MD; Y.H. Chien, MD; R. Hopkin, MD; S. Vijayaraghavan, MD; \\ D. Gruskin, MD, PhD; D. Bartholomew, MD; A. van der Ploeg, MD, PhD; J.P. Clancy, MD; R. Parini, MD; \\ G. Morin, MD; M. Beck, MD, PhD; G.S. De la Gastine, MD; M. Jokic, MD; B. Thurberg, MD, PhD; \\ S. Richards, PhD; D. Bali, PhD; M. Davison, MD; M.A. Worden, BS; Y.T. Chen, MD, PhD; and J.E. Wraith, MD
}

\begin{abstract}
Background: Pompe disease is a progressive metabolic neuromuscular disorder resulting from deficiency of lysosomal acid $\alpha$-glucosidase (GAA). Infantile-onset Pompe disease is characterized by cardiomyopathy, respiratory and skeletal muscle weakness, and early death. The safety and efficacy of recombinant human (rh) GAA were evaluated in 18 patients with rapidly progressing infantile-onset Pompe disease. Methods: Patients were diagnosed at 6 months of age and younger and exhibited severe GAA deficiency and cardiomyopathy. Patients received IV infusions of rhGAA at $20 \mathrm{mg} / \mathrm{kg}$ $(\mathrm{n}=9)$ or $40 \mathrm{mg} / \mathrm{kg}(\mathrm{n}=9)$ every other week. Analyses were performed 52 weeks after the last patient was randomized to treatment. Results: All patients (100\%) survived to 18 months of age. A Cox proportional hazards analysis demonstrated that treatment reduced the risk of death by $99 \%$, reduced the risk of death or invasive ventilation by $92 \%$, and reduced the risk of death or any type of ventilation by $88 \%$, as compared to an untreated historical control group. There was no clear advantage of the 40-mg/kg dose with regard to efficacy. Eleven of the 18 patients experienced 164 infusion-associated reactions; all were mild or moderate in intensity. Conclusions: Recombinant human acid $\alpha$-glucosidase is safe and effective for treatment of infantile-onset Pompe disease. Eleven patients experienced adverse events related to treatment, but none discontinued. The young age at which these patients initiated therapy may have contributed to their improved response compared to previous trials with recombinant human acid $\alpha$-glucosidase in which patients were older.
\end{abstract}

NEUROLOGY 2007;68:99-109

\section{Editorial, see page 88 . \\ See also page 110 .}

This article was previously published in electronic format as an Expedited E-pub at www.neurology.com

From the Department of Pediatrics (P.S.K., M.M., J.L., D.B.), Duke University Medical Center, Durham, NC; Genzyme Corporation (D.C., B.T., S.R.,

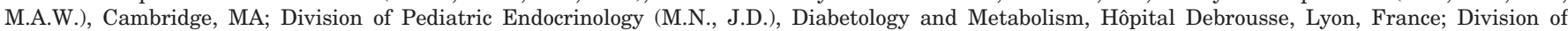
Pediatrics (B.B., C.S.), Shands Hospital at University of Florida, Gainesville, FL; Metabolic Unit (H.M., M.H.), Rambam Medical Centre, Haifa, Israel;

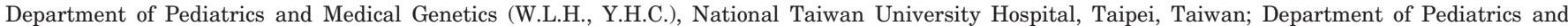

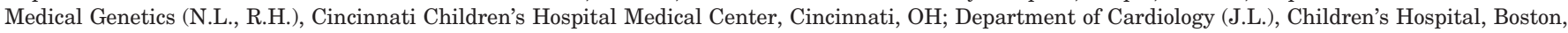
MA; Willink Biochemical Genetics Unit (S.V., J.E.W.), Royal Manchester Children's Hospital, Manchester, UK; Department of Genetics (D.G.), Emory

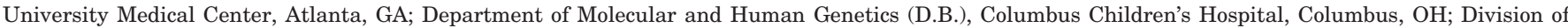

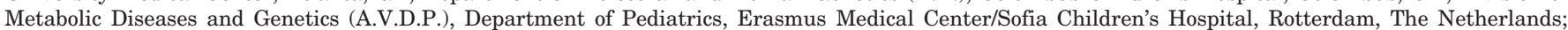

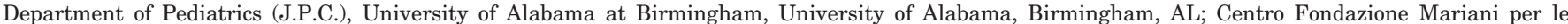

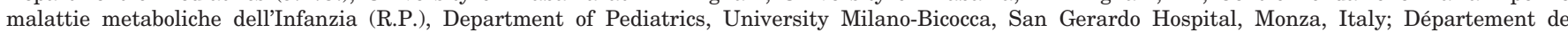
Pédiatrie (G.M.), CHU Amiens, Amiens, France; Metabolic Unit (M.B.), Universitäts-Kinderklinik Mainz, Mainz, Germany; Pediatric Intensive Care Unit

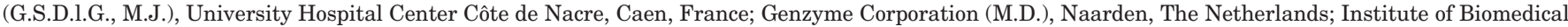
Sciences (Y.T.C.), Academica Sinica, Taipei, Taiwan.

*These authors contributed equally to this study.

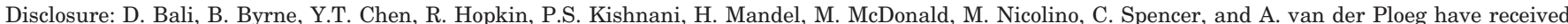

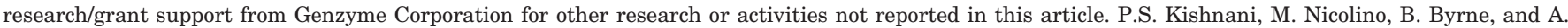

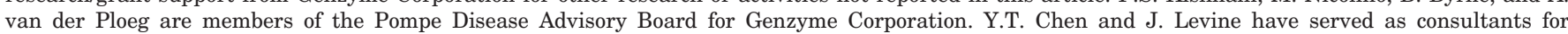
Genzyme. J. Levine, J.E. Wraith, C. Spencer, M. McDonald, Y.T. Chen, R. Hopkin, P.S. Kishnani, M. Nicolino, and H. Mandel have received honoraria from

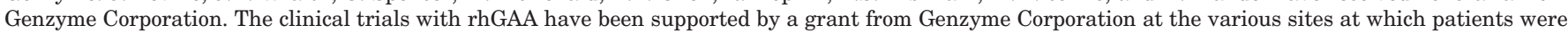
treated. rhGAA, in the form of Genzyme's product Myozyme has now been approved in the United States, Canada, and the European Union as therapy for

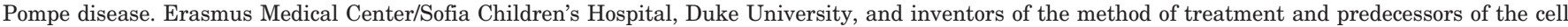

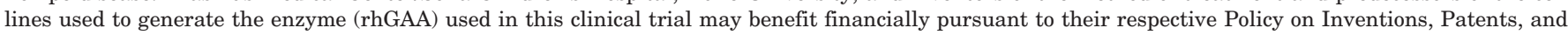
Technology Transfer, even if those cell lines are not used in the commercialized therapy.

Received May 17, 2006. Accepted in final form October 10, 2006.

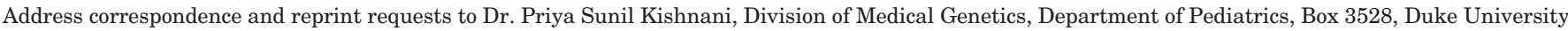
Medical Center, Durham, NC 27710; e-mail: kishn001@mc.duke.edu 
Pompe disease, also known as glycogen storage disease type II or acid maltase deficiency, is a rare, progressively debilitating, and often fatal lysosomal storage disorder. Patients with Pompe disease have an autosomal-recessively inherited deficiency of the enzyme acid $\alpha$-glucosidase (GAA), which hydrolyzes glycogen to glucose. This GAA deficiency causes glycogen to accumulate in multiple tissues, especially skeletal and cardiac muscle. Glycogen deposits disrupt muscle cytoarchitecture and function, causing progressive motor, respiratory, and cardiac dysfunction. ${ }^{1}$

Patient age at the onset of Pompe disease symptoms and the rate of deterioration can vary considerably. ${ }^{1}$ Patients with infantile-onset Pompe disease experience symptoms within the first year of life and progress rapidly to death. In other patients, symptoms are exhibited later and the disease progresses more slowly, but it is still associated with significant morbidity. Patients with early onset of symptoms typically manifest hypotonia, muscle weakness, and cardiomyopathy within the first months of life. The outlook for these patients is grim; they fail to acquire or lose motor developmental milestones, and cardiorespiratory failure and death usually occur before 1 year of age. ${ }^{2-4}$ Slonim et al. ${ }^{5}$ described a subset of infantile-onset patients with less severe cardiac involvement (i.e., less severe cardiomyopathy and a lack of cardiomegaly before the age of 6 months) who survived longer with ventilatory support. However, a recent retrospective chart review found early cardiomegaly even among first-birthday survivors. ${ }^{6}$ In this historical cohort, early symptom onset was associated with early demise.

In early clinical trials, IV enzyme replacement with different forms of recombinant human (rh) GAA has improved survival, cardiac and respiratory function, and motor development in severely affected infants. $^{7-11}$ A subset of these treated patients achieved independent ambulation. In a recent trial of rhGAA derived from transfected Chinese hamster ovary cells, eight of eight infants showed cardiac improvement, six were alive, and five were free of invasive ventilation after 52 weeks of treatment, and five attained new motor milestones. ${ }^{11}$ Of the three patients who eventually achieved the ability to walk independently, all had begun treatment prior to the age of 6 months, suggesting that early treatment may be critical for the optimal motor response to treatment. ${ }^{11}$ In this multicenter, multinational, open-label, dose-ranging study, we examined the safety and efficacy of rhGAA treatment in a larger cohort of severely affected patients with Pompe disease who began treatment prior to 6 months of age.

Methods. Study design and treatment. Local institutional review boards or independent ethics committees approved protocols and consent forms at each of 13 primary sites (six centers in the Untied States, five in Europe, one in Taiwan, and one in Israel). Parents or guardians gave written informed consent for patients' participation. An independent data safety monitoring board reviewed safety; an independent allergic reaction review board was consulted, if required, for issues related to serious infusionassociated reactions (IARs).

Eligible patients had documented symptoms of infantile-onset Pompe disease, including skin fibroblast GAA activity $<1 \%$ of the normal mean and hypertrophic cardiomyopathy (left ventricular mass index $\geq 65 \mathrm{~g} / \mathrm{m}^{2}$ by echocardiogram); they were no older than 26 weeks at enrollment. Exclusion criteria included respiratory insufficiency $\left(\mathrm{O}_{2}\right.$ saturation $<90 \%$ or $\mathrm{CO}_{2}$ partial pressure $>55$ $\mathrm{mm} \mathrm{Hg}$ [venous] or $>40 \mathrm{~mm} \mathrm{Hg}$ [arterial] in room air or any ventilator use), a major congenital anomaly or clinically significant intercurrent illness unrelated to Pompe disease, or any prior GAA treatment. A total of 18 patients were studied.

Parents or legal guardians were informed that the protocoldefined stopping rules related to the occurrence of serious adverse events (AEs) and allowed for temporary or permanent patient discontinuation if the investigator, safety review board, and sponsor determined there was a significant risk to patient safety.

It was considered unethical to include a placebo group as part of the study design for the following reasons: 1) infantile-onset Pompe disease is a rapidly fatal disorder and 2) early clinical trials have shown that treatment with various forms of rhGAA can improve survival, cardiac and respiratory function, growth, and motor development in severely affected infants. ${ }^{7-11}$ Thus, a historical control group of 61 severely affected infants 6 months old and younger was identified by applying the study inclusion and exclusion criteria to a group of 168 patients with infantileonset Pompe disease identified through a retrospective chart review. ${ }^{6}$ The cohort included 168 patients from nine countries, 33 different sites, with birth dates ranging from before 1985 to $2002 .{ }^{6}$ Drug effects on overall survival (with or without ventilator use) and invasive ventilator-free survival were compared between treated patients and this historical cohort; our group of 18 treated patients provided $>98 \%$ power to detect a difference between treated and control groups. Table 1 summarizes the screening criteria applied to the original historical patient population in order for patients to be included in the historical control subgroup.

Alglucosidase alfa, which contains rhGAA produced in Chinese hamster ovary cells, was supplied by Genzyme Corporation. A simple randomization scheme was used to assign patients to the two dose groups. Upon confirmation that patients met all eligibility criteria and completion of pretreatment screening and baseline assessments, eligible patients were randomized in a $1: 1$ ratio to receive an IV infusion of either $20 \mathrm{mg} / \mathrm{kg}$ or $40 \mathrm{mg} / \mathrm{kg}$ of $\mathrm{rhGAA}$ every other week. Clinicians and patients were not blinded to the dose of rhGAA used. The total amount of rhGAA administered could be adjusted every 4 weeks to account for changes in body weight.

Clinical assessments of safety and efficacy. Patients were observed and their vital signs were monitored during rhGAA infusion and for 2 hours afterward. Safety assessments included evaluating blood and urine chemistry (data not shown), the occurrence and timing of the development of anti-rhGAA IgG antibodies (assayed at first rhGAA infusion and every 4 weeks thereafter), and the incidence and nature of AEs, including IARs.

Efficacy was measured by assessing survival, ventilator use, left ventricular mass by echocardiography, growth (weight and length), muscle GAA activity and glycogen levels, motor development (using the Alberta Infant Motor Scale [AIMS] ${ }^{12}$ ), and level of disability (using an adaptation of the Pediatric Evaluation of Disability Index [PEDI $]^{13}$ developed for Pompe disease. ${ }^{14,15}$ Although not an efficacy endpoint, cognitive development (using Bayley's Scales of Infant Development, Second Edition [BSID-II]) was also serially evaluated. ${ }^{16}$ Echocardiograms and glycogen content in muscle biopsy samples were centrally read by a pediatric cardiologist and a pathologist who were blinded to dose, patient, and time point. Motor and cognitive evaluations were centrally scored by a nonblinded central clinician.

Survival and ventilation data were analyzed up to 18 months of age, as compared to survival of the historical control group; all other efficacy data were analyzed with respect to changes from baseline after 52 weeks of treatment. The primary efficacy endpoint was the Kaplan-Meier ${ }^{17}$ proportion of patients alive and free of invasive ventilation at 18 months of age. Safety data were analyzed for the duration of treatment. Because patients were enrolled over a period of 1 year, safety data ranged from 52 weeks for the last patient randomized to treatment to 106 weeks for the first patient treated with rhGAA. 
Table 1 Summary of study inclusion and exclusion criteria applied to patients in the historical control group

\begin{tabular}{|c|c|}
\hline Category & No. $(\%)$ of patients \\
\hline \multicolumn{2}{|c|}{ Inclusion criteria* } \\
\hline \multicolumn{2}{|c|}{$\begin{array}{l}\text { Documented cardiomyopathy first } \\
\text { identified by } \leq 26 \text { wk of age }\end{array}$} \\
\hline Yes & $115(68.5)$ \\
\hline No & $53(31.5)$ \\
\hline \multicolumn{2}{|c|}{ Confirmed diagnosis by $\leq 26$ wk of age } \\
\hline Yes & $112(66.7)$ \\
\hline No & $56(33.3)$ \\
\hline \multicolumn{2}{|c|}{ First symptoms by $\leq 26$ wk of age } \\
\hline Yes & $153(91.1)$ \\
\hline No & $15(8.9)$ \\
\hline \multicolumn{2}{|c|}{ Exclusion criteria* } \\
\hline \multicolumn{2}{|c|}{$\begin{array}{c}\text { GAA activity level }>1 \% \text { of the } \\
\text { mean of the normal range }\end{array}$} \\
\hline Yes & 0 \\
\hline No & $168(100.0)$ \\
\hline \multicolumn{2}{|c|}{$\begin{array}{l}\mathrm{LVMI}<65 \mathrm{~g} / \mathrm{m}^{2} \text { at the last visit } \\
\text { prior to } 26 \mathrm{wk} \text { of age }\end{array}$} \\
\hline Yes & $1(0.6)$ \\
\hline No & $167(99.4)$ \\
\hline \multicolumn{2}{|c|}{ Documented major congenital abnormality } \\
\hline Yes & $12(7.1)$ \\
\hline No & $156(92.9)$ \\
\hline \multicolumn{2}{|c|}{$\begin{array}{l}\text { Clinically significant disease(s) } \\
\text { (with the exception of symptoms } \\
\text { relating to Pompe disease) }\end{array}$} \\
\hline Yes & $37(22.0)$ \\
\hline No & $131(78.0)$ \\
\hline \multicolumn{2}{|c|}{$\begin{array}{l}\text { Any known ventilator use between } \\
0 \text { and } 6 \text { mo of age, due to reasons other } \\
\text { than procedure-related use }\end{array}$} \\
\hline Yes & $25(14.9)$ \\
\hline No & $143(85.1)$ \\
\hline \multicolumn{2}{|c|}{ All eligibility criteria met } \\
\hline Yes & $62 \dagger(36.9)$ \\
\hline No & $106(63.1)$ \\
\hline
\end{tabular}

All age calculations were corrected for gestation.

* "No" may include patients for whom data were unavailable.

$\uparrow$ Although 62 patients met the eligibility criteria for the historical control group, one patient was excluded because the date of death was unavailable.

LVMI = left ventricular myocardial index.

GAA activity assay. Cultured skin fibroblasts and muscle biopsy tissue obtained from patients were assayed for GAA activity against 4-methylumbelliferyl $\alpha$-d-glucoside in an assay similar to the method of Reuser et al. ${ }^{18}$ and described in detail in Kishnani et al. ${ }^{11}$

Biochemical glycogen determination. Open quadriceps muscle biopsies were performed at baseline and weeks and week 52 . Biopsy samples taken at weeks 12 and 52 were obtained 48 hours after the regularly scheduled rhGAA infusion for that visit. A 0.5 $\times 0.5 \times 3$-cm sample was taken from alternating sides at each time point under general, regional, or local anesthesia. Methods for glycogen quantification were performed as described in Kishnani et al. ${ }^{11}$

Briefly, for biochemical analysis, muscle tissues were homogenized, centrifuged, boiled, and treated with amyloglucosidase to digest the glycogen. The glucose produced was quantified with a Glucose Trinder Kit (Sigma, St. Louis, MO).

Biochemical measurements of glycogen levels in skeletal muscle of normal children are not available. Therefore, changes in glycogen content were compared between baseline and week 52 within individual patients.

Anti-rhGAA antibody testing. Serum samples were taken prior to each infusion from initiation of therapy through week 24 , and subsequently at weeks $38,52,64,78,90$, and 104 . As discussed above, different patients received different durations of rhGAA treatment, ranging from 52 to 106 weeks, depending on when they enrolled in the study. The presence of IgG antibodies to rhGAA was assessed using enzyme-linked immunosorbent assays and confirmed using radioimmunoprecipitation, as described in Kishnani et al. ${ }^{11}$

Genotyping. DNA was isolated from the peripheral blood of patients and sequenced. GAA mutation analysis was determined by Genzyme Corporation, as described previously. ${ }^{11}$

Cross-reacting immunologic material (CRIM) status. CRIM status was determined as described previously. ${ }^{11}$ Briefly, cell lysates derived from patients' fibroblasts were subjected to Western blot analysis with a pool of monoclonal antibodies that recognize both native and recombinant GAA. A patient was considered to be CRIM positive if the presence of any of these forms of GAA was detected in samples prepared from patient fibroblasts in the Western blot assay.

Results. Disposition of patients. A total of 20 patients were evaluated for eligibility to participate in this study (figure 1). Two patients were excluded from the study; one was determined not to have Pompe disease based on GAA activity levels. The other required ventilation during the baseline period before receiving any treatment. This patient was discontinued from the study because the use of any ventilation at the time of enrollment was an exclusion criterion but went on to receive rhGAA under an expanded access program.

As discussed previously, it was considered unethical to administer placebo treatment to patients in this study. The trial was designed to show a positive drug effect on survival, as compared to a historical control population. A retrospective review was performed on the medical records of an international cohort of 168 patients with infantileonset Pompe disease who did not receive treatment. ${ }^{6} \mathrm{~A}$ subset of 62 patients (referred to as the historical control group) from within this cohort was selected based on the screening criteria for the clinical trial, including age at first symptoms, age at diagnosis, presence of cardiomyopathy by 6 months of age, GAA activity, and congenital abnormalities, as summarized in table 1 . One of the 62 patients was excluded from the survival analyses because the date of death was unavailable. This historical control group of 61 untreated patients was used as a comparator population for the severely ill infantile-onset rhGAAtreated patients in this study.

Demographics. Demographic data are summarized in table 2. For rhGAA-treated patients, the median age at presentation was 1.0 month, 4.3 months at postnatal diagnosis (one patient was diagnosed prenatally), and 5.3 months at first rhGAA infusion. At enrollment, ages of patients born before 40 weeks were corrected for gestation. Patients in the clinical trial and historical control subjects 


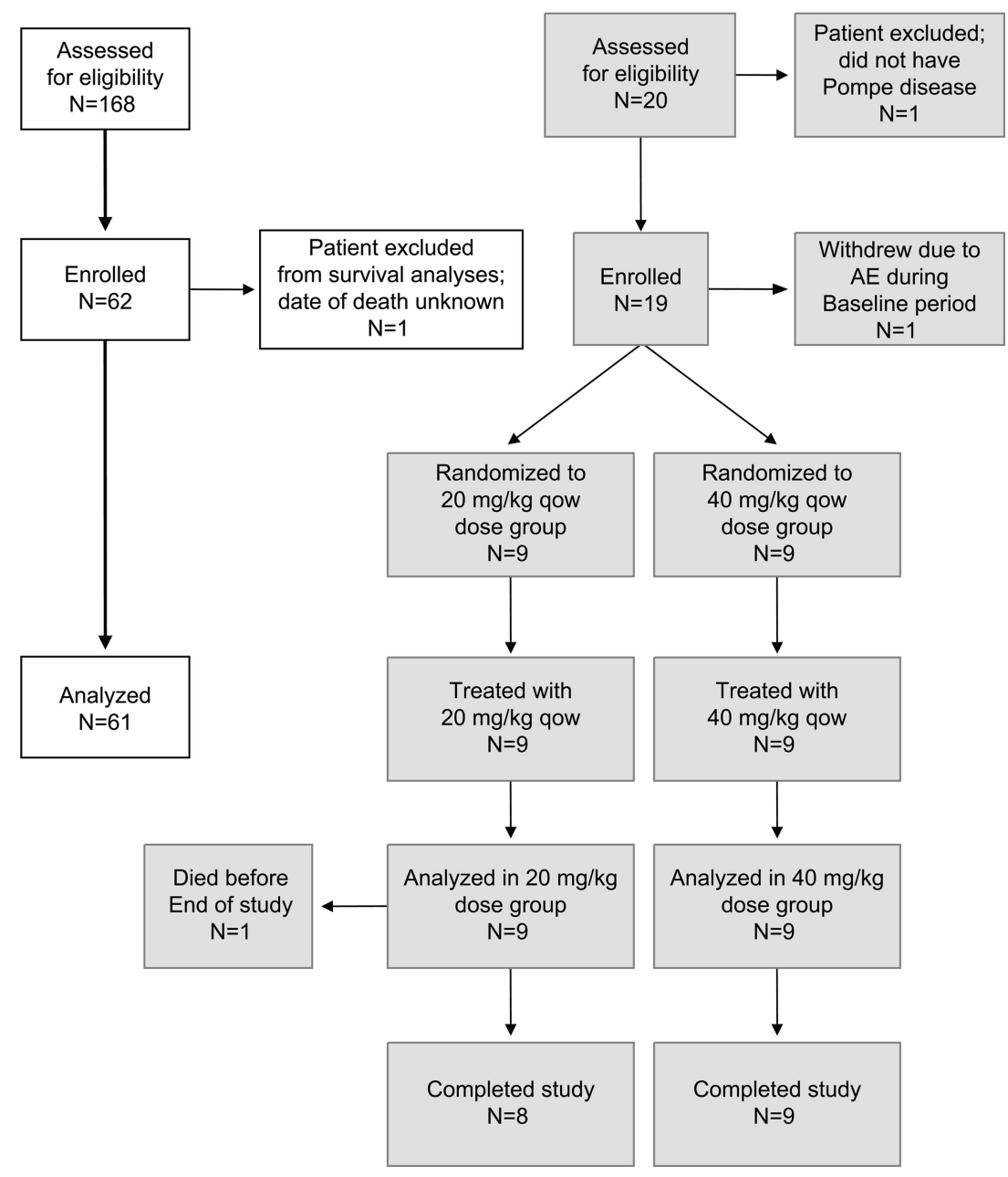

Figure 1. Disposition of patients in historical control group and recombinant human acid $\alpha$-glucosidase-treated group. had similar demographic profiles in terms of age, gender, and ethnicity, as shown in table 2.

Survival and ventilator use. Survival. Fifteen of the 18 treated patients reached the age of 18 months by the end of the study; three patients were right-censored from this analysis because they had not reached the age of 18 months by the end of the study, although they were alive at that time (at ages 15.9 months, 17.9 months, and 14.4 months). This is in striking contrast to what was observed in the untreated historical control group, in which only one of 61 patients survived to the age of 18 months (1.9\%; 95\% CI: $0 \%$ to $5.5 \%$ ). A Kaplan-Meier analysis of overall 18month survival is shown in figure $2 \mathrm{~A}$

Invasive ventilator use. Of the six patients who required ventilatory assistance, three patients (including one who had not reached the age of 18 months by the end of the study) required invasive ventilation beginning at 9.1, 9.2 , and 15.0 months of age. Invasive ventilation was defined as requiring passive ventilation through an endotracheal tube or tracheostomy. The other two patients who had not reached the age of 18 months by the end of the study were right-censored from this analysis, although they were free of invasive ventilatory support at that time. The remaining 13 patients were free of invasive ventilatory support at the age of 18 months. Thus, the KaplanMeier invasive ventilation-free survival rate (the primary efficacy endpoint) was $88.9 \%$ (95\% CI: $74.4 \%$ to $100 \%$ ); far greater than the survival rate for untreated patients (figure $2 \mathrm{~B}$ ).

Any ventilator use. Six patients, including one who had not reached the age of 18 months by the end of the study, required ventilatory support (invasive or noninvasive, beginning at ages ranging from 7.8 to 14.8 months). The other two patients who had not reached the age of 18 months by the end of the study were right-censored from this analysis, although they were free of any ventilatory support at that time. The remaining 10 patients were ventilator independent, for a Kaplan-Meier ventilator-free survival rate of $66.7 \%$ (95\% CI: $44.9 \%$ to $88.4 \%$ ) (figure $2 \mathrm{C})$. Again, this is much higher than the overall survival rate in the untreated historical control group.

Cox proportional hazards analysis. A Cox proportional hazards analysis ${ }^{19}$ with model terms of age at diagnosis, age at symptom onset, and treatment as a time-varying covariate was used to compare the risk of an event for treated patients to the untreated historical control group. rhGAA treatment was found to reduce the risk of death by $99 \%$ (hazard ratio of $0.01,95 \%$ CI: 0.00 to $0.10, p<0.001$ ), the risk of death or invasive ventilation by $92 \%$ (hazard ratio of $0.08,95 \% \mathrm{CI}: 0.03$ to $0.21, p<0.001$ ), and the risk of death or any type of ventilation by $88 \%$ (hazard ratio of $0.12,95 \%$ CI: 0.05 to $0.29, p<0.001$ ).

Cardiac response. All patients had echocardiographic evidence of cardiomyopathy at enrollment. Additional 


\begin{tabular}{|c|c|c|c|}
\hline Parameter & $\begin{array}{l}\text { rhGAA-treated } \\
\text { patients } \\
(\mathrm{n}=18)\end{array}$ & $\begin{array}{l}\text { Historical } \\
\text { control group } \\
\mathrm{n}=62)\end{array}$ & $\begin{array}{l}\text { Overall natural } \\
\text { history population } \\
\quad(\mathrm{n}=168)^{*}\end{array}$ \\
\hline \multicolumn{4}{|l|}{ Gender, n (\%) } \\
\hline Male & $11(61.1)$ & $28(45.2)$ & $83(49.4)$ \\
\hline Female & 7 (38.9) & $34(54.8)$ & $85(50.6)$ \\
\hline \multicolumn{4}{|l|}{ Race, n (\%) } \\
\hline White & $7(38.9)$ & $31(50.0)$ & $80(47.6)$ \\
\hline Black & $4(22.2)$ & $4(6.5)$ & $22(13.1)$ \\
\hline Hispanic & $2(11.1)$ & $1(1.6)$ & $1(0.6)$ \\
\hline Asian & $3(16.7)$ & $18(29.0)$ & $52(31.0)$ \\
\hline Other & $2(11.1)$ & $1(1.6)$ & $1(0.6)$ \\
\hline Unknown & 0.0 & $7(11.3)$ & $12(7.1)$ \\
\hline \multicolumn{4}{|c|}{ Age at first symptoms, mo } \\
\hline $\mathrm{n}$ & 18 & 62 & 166 \\
\hline Mean & 1.6 & 1.9 & 2.7 \\
\hline Median & 1.0 & 1.6 & 2.0 \\
\hline SD & 1.78 & 1.79 & 2.48 \\
\hline Min, $\max$ & 0.05 .5 & 0.05 .9 & $0.0,12.0$ \\
\hline \multicolumn{4}{|c|}{ Age at diagnosis, mo $\dagger^{\dagger}$} \\
\hline $\mathrm{n}$ & 18 & 62 & 165 \\
\hline Mean & 3.7 & 3.6 & 6.0 \\
\hline Median & 4.3 & 4.1 & 4.7 \\
\hline SD & 2.17 & 1.94 & 8.83 \\
\hline Min, $\max$ & $0.2,6.8$ & $-4.4,6.6$ & $-5.1,84.2$ \\
\hline \multicolumn{4}{|c|}{ Age at first infusion, $\operatorname{mo} \ddagger$} \\
\hline $\mathrm{n}$ & 18 & NA & NA \\
\hline Mean & 4.6 & NA & NA \\
\hline Median & 5.3 & NA & NA \\
\hline SD & 1.67 & NA & NA \\
\hline Min, $\max$ & $1.2,6.1$ & NA & NA \\
\hline \multicolumn{4}{|c|}{ Age at death in historical reference group } \\
\hline $\mathrm{n}$ & NA & $61 \S$ & 163 \\
\hline Median (95\% CI) & NA & $7.5(6.7-8.6)$ & $8.7(8.2-9.4)$ \\
\hline Min, $\max$ & NA & $0.3,43.9$ & $1.6,56.9$ \\
\hline
\end{tabular}

* Kishnani et al. ${ }^{6}$

$\dagger$ Negative values are indicative of prenatal diagnoses.

$\ddagger$ Note that ages at first infusion were corrected for gestational age in patients who were born before 40 weeks.

$\S$ One patient was excluded from this analysis as date of death was unknown; a total of 55 of 61 (88.7\%) patients died; six were right-censored.

II A total of 141 of 163 (86.5\%) patients died; 22 were right-censored.

$\mathrm{NA}=$ not applicable.

echocardiograms were performed at baseline and at weeks $4,8,12,26,38$, and 52 . The mean baseline left ventricular mass index was $193.4 \mathrm{~g} / \mathrm{m}^{2}(\mathrm{n}=15$; range 59.3 to 301.8 $\mathrm{g} / \mathrm{m}^{2}$ ). At week 52, mean left ventricular mass index had declined to $86.8 \mathrm{~g} / \mathrm{m}^{2}$ ( $\mathrm{n}=15$; range 44.9 to $157.3 \mathrm{~g} / \mathrm{m}^{2}$ ). Treatment decreased left ventricular mass as early as week 4 , as summarized in figure 3 , which shows that mean left ventricular mass $Z$ scores decreased from 7.1 at baseline to 3.3 by the end of the 52 -week treatment period.
Ejection fraction was also measured by echocardiography to provide a gross and noninvasive measure of ventricular function. At baseline, the mean ejection fraction was $51.2 \%$ ( $\mathrm{n}=16$, range 25.3 to $75.9 \%$ ), and at week 52 , the mean ejection fraction was essentially unchanged, at $54.9 \%(\mathrm{n}=18$, range 24.4 to $75.6 \%)$. It is important to note that measurement of cardiac function through noninvasive methods such as echocardiograms is imprecise in subjects with evidence of left ventricular hypertrophy. ${ }^{20}$ More inva- 

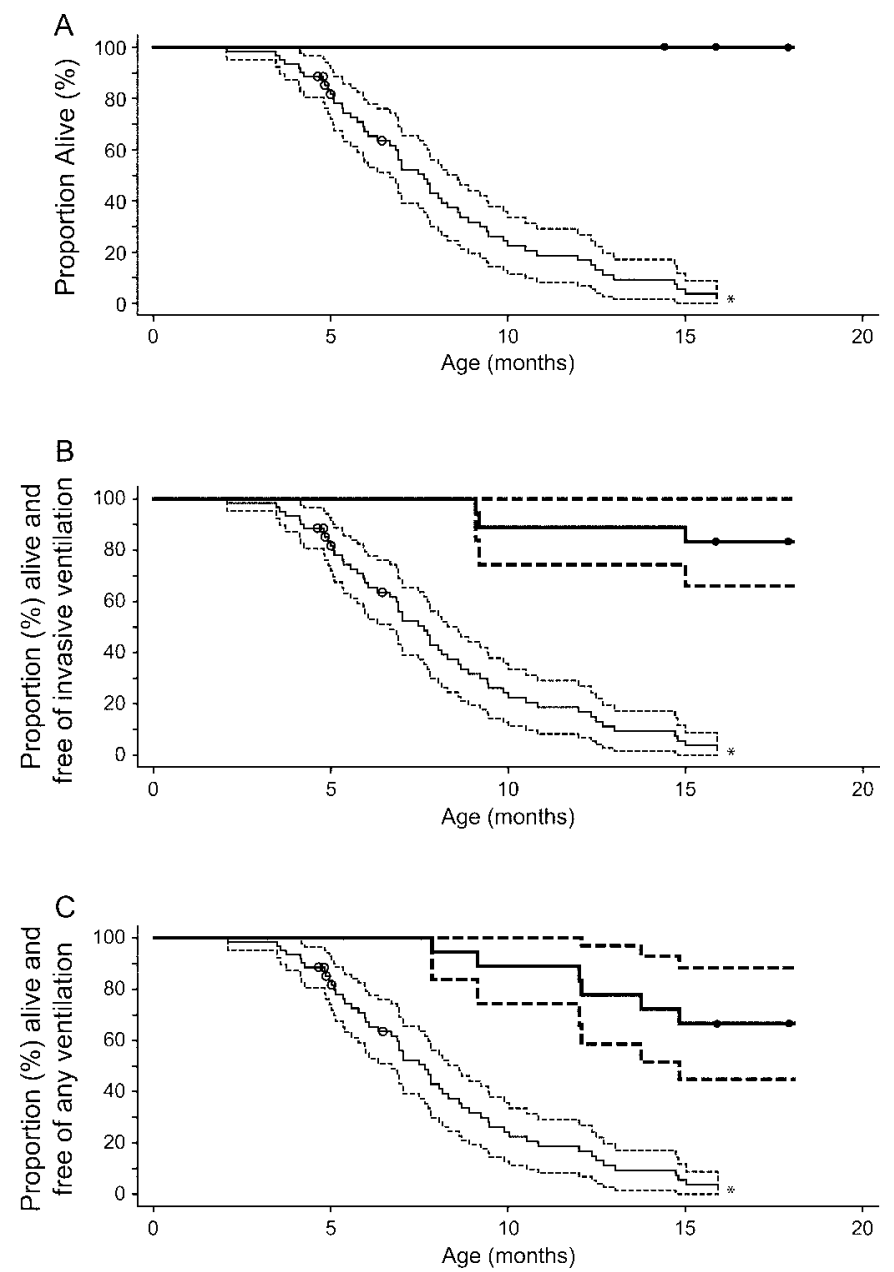

Figure 2. (A) Kaplan-Meier estimate of time from date of birth to death. Three patients were right-censored from this analysis (at ages 14.4, 15.9, and 17.9 months) because they had not reached the age of 18 months by the end of the study, although they remained alive at that time. (B) Kaplan-Meier estimate of time from birth to invasive ventilator use or death. Two patients were right-censored from this analysis (at ages 15.9 and 17.9 months) because they had not reached the age of 18 months by the end of the study, although they remained free of any ventilatory support that time. One patient who had not reached the age of 18 months by the end of the study required invasive ventilatory support and was therefore not right-censored but was designated as failing this endpoint. (C) Kaplan-Meier estimate of time from birth to any ventilator use or death. Two patients were right-censored from this analysis (at ages 15.9 and 17.9 months) because they had not reached the age of 18 months by the end of the study, although they remained free of any ventilatory support that time. One patient who had not reached the age of 18 months by the end of the study required ventilatory support and was therefore not right-censored but was designated as failing this endpoint. In each panel, thick solid lines show the Kaplan-Meier estimates for the treated patient group; thin solid lines show those for the historical control group, with 95\% CIs given by the corresponding dashed lines. Solid circles indicate right-censored observations. *Asterisk indicates that one patient from the historical control group remained alive at 18 months of age; this patient died at age 44 months.

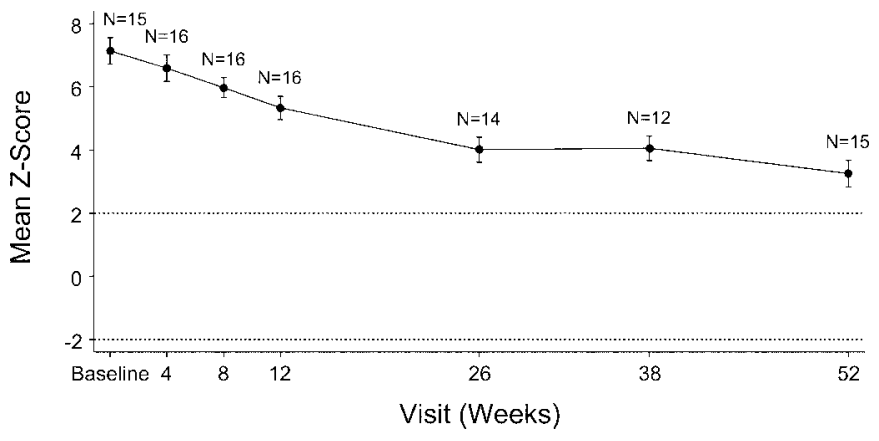

Figure 3. Mean left ventricular mass $Z$ scores of treated patients from baseline to week 52; vertical bars represent standard error.

sive procedures to measure cardiac function were not used because of the risk associated with these procedures and the compromised state of many of these patients at study entry.

In patients with neuromuscular disorders and respiratory insufficiency, it can be difficult to specifically diagnose cardiac failure, as the symptoms for both are similar. As discussed above, echocardiographic evaluation by itself may not accurately reflect cardiac dysfunction in patients with left ventricular hypertrophy. The presence of clinical signs and symptoms of cardiac failure was evaluated at regular intervals by the investigators, who were asked to report AEs that were considered specific to or suggestive of cardiac failure. According to these criteria, two of 18 patients $(11.1 \%)$ had findings compatible with cardiac failure prior to rhGAA administration (from screening to day 0), assessed as described above (Patients $\mathrm{H}$ and $\mathrm{M}$, both assigned to the $20-\mathrm{mg} / \mathrm{kg}$ dose group). By week 52 , no patients had findings compatible with cardiac failure; Patients $\mathrm{H}$ and $\mathrm{M}$ had recovered clinically.

Physical growth. Normal weight and length were considered as values above the third percentile. ${ }^{21}$ Fifteen of the 18 patients maintained weight above the third percentile during treatment. The three patients who failed to maintain normal weight had weights below the third percentile prior to rhGAA treatment and were tube fed. In contrast, only two of the patients who maintained weight above the third percentile were tube fed. Notably, $53 \%$ of untreated infantile Pompe disease patients failed to thrive. ${ }^{6}$ In terms of length, 15 of 16 patients maintained normal length-for-age percentiles during treatment.

Motor and cognitive development. Thirteen of 18 patients made consistent motor and functional gains on the Alberta Infant Motor Scale from baseline to week 52 (data not shown). Seven of these patients were considered to be walkers as they were able to walk independently by week 52. Three patients could pull to stand independently and walk with hands held by week 52 ; these patients were considered to be standers. Three patients could roll and sit independently, but were unable to bear weight through the legs and were therefore designated as functional sitters. The remaining five patients did not make substantial gains in AIMS scores from baseline to week 52.

The Pompe PEDI was specifically designed to evaluate functional skills in patients with Pompe disease ${ }^{14,15}$ and includes three content domains: mobility, self-care, and social skills. The seven patients designated as walkers based on the AIMS assessments also acquired the most 


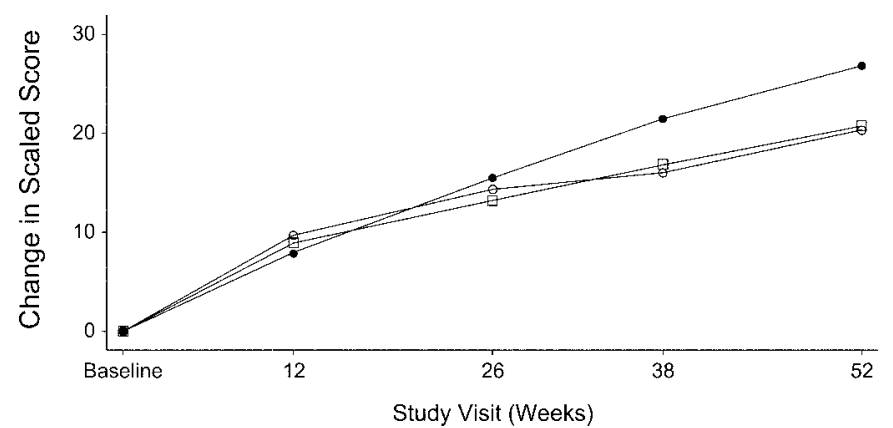

Figure 4. Change from baseline to week 52 in Pompe Pediatric Evaluation of Disability Inventory scaled scores. Open circles: self-care (predominantly upper limb skills); open squares: mobility (predominantly lower limb skills); filled circles: social function (interactive play with adults, play with objects). Scaled scores compare patients' performance against themselves at baseline. The graph represents average data from all patients $(N=18)$, except at week 12, where $n=17$.

skills in the Pompe PEDI, including (but not limited to) such skills as self-feeding, playing independently, climbing stairs, and naming objects. The three patients designated as standers also made substantial gains in all three domains of the Pompe PEDI, although they did not acquire as many skills as the walkers. The three patients designated as functional sitters demonstrated modest gains on the Pompe PEDI. These patients acquired skills like head control and independent play with objects in a sitting position, as well as some basic communication skills. The remaining five patients did not make substantial gains in the AIMS or the Pompe PEDI assessments. A summary of the gains made by the all patients in each content domain of the Pompe PEDI are shown in figure 4.

All patients acquired cognitive, language, and personal/ social development skills during the 52-week treatment period, although some patients acquired these skills more slowly than same-age peers. For example, by week 52 , nine of the 17 patients (53\%) who were evaluated with the BSID-II at baseline and at week 52 had mental development index (MDI) scores within normal limits (85 to 115), whereas four patients had MDI scores indicating mildly delayed performance (70 to 84), and four patients had MDI scores consistent with significantly delayed performance (s69) (data not shown). It is important to note that the motor involvement typical of patients with Pompe disease interferes with the assessment of integrated oral-motor and fine-motor skills required for the administration of the BSID-II. In addition, hearing loss, which was recently recognized as a complication of infantile-onset Pompe disease, ${ }^{22}$ could interfere with cognitive testing.

Muscle GAA activity and glycogen content. We assayed GAA activity and glycogen content in quadriceps muscle biopsy specimens taken at baseline and weeks 12 and 52 . At baseline, mean quadriceps GAA activity was $1.22 \mathrm{mmol} /$ $\mathrm{h} / \mathrm{g}(\mathrm{n}=18$, range 0.0 to 8.8$)$; in 15 patients, activity was below quantifiable limits $(<3.3 \mathrm{nmol} / \mathrm{h} / \mathrm{g}$ tissue). Overall, GAA activity increased markedly during treatment to a mean value of $205 \mathrm{mmol} / \mathrm{h} / \mathrm{g}(\mathrm{n}=16$, range 49.0 to 1,298.3). This effect was larger in the $40-\mathrm{mg} / \mathrm{kg}$ dose group than in the $20-\mathrm{mg} / \mathrm{kg}$ dose group. In the $40-\mathrm{mg} / \mathrm{kg}$ dose group, mean GAA levels increased from 0.00 to 310.05 $\mathrm{nmol} / \mathrm{h} / \mathrm{g}$, whereas in the $20-\mathrm{mg} / \mathrm{kg}$ dose group, mean GAA levels increased from 2.43 to $100.30 \mathrm{nmol} / \mathrm{h} / \mathrm{g}$. GAA activity levels in individual patients at baseline and week 52 are shown in table 3.

Baseline muscle glycogen content (measured biochemically) ranged from 1.2 to $11.3 \mathrm{mg} / \mathrm{g}$ tissue (wet weight). Fifteen of the 17 patients who had glycogen levels evaluated at week 52 exhibited stable $( \pm 20 \%)$ or decreased muscle glycogen content ( $>20 \%$ glycogen depletion) as compared to baseline. Twelve of these 15 patients made motor gains during the 52 -week treatment period, as shown in table 3 . None of the three patients whose muscle glycogen content increased $>20 \%$ from baseline during treatment showed any meaningful motor improvements.

Adverse events/infusion-associated reactions. Eleven of the 18 patients in this study experienced 164 IARs, which were defined as treatment-related AEs that occurred following infusion onset up to and including the postinfusion observation period. All the IARs were assessed as mild or moderate in intensity; none were severe. The most common IARs were rash (24 events), fever (23 events), urticaria (22 events), and decreased oxygen saturation (18 events). Overall, IARs occurred in the following organ systems: skin (urticaria, rash, erythema, livedo reticularis, and pruritus); respiratory (cough, tachypnea, rales, decreased oxygen saturation); gastrointestinal (vomiting, retching, gastroesophageal reflux); cardiac (tachycardia, cyanosis, decreased heart rate); vascular (flushing, hypertension, hypotension, pallor); psychiatric (agitation, irritability, restlessness); nervous system (tremor), and general disorders (fever and rigors). IARs were typically managed by slowing or interrupting infusions, and all 11 patients who experienced IARs recovered without sequelae. No patient discontinued treatment because of IARs or AEs.

One patient (Patient D) died of desaturation and bradycardia following hospitalization for treatment of respiratory distress and pneumonia at study week 61 (at the age of 19.8 months), after the patient had completed 52 weeks of treatment, but before the study ended. The death was assessed as being unrelated to rhGAA treatment. The most prominent histologic findings on autopsy were the presence of glycogen in skeletal muscle (various samples from upper and lower extremities and the diaphragm) and cardiomyocytes. Glycogen was also evident in the smooth muscle cell layers of the gastrointestinal tract, particularly upper esophagus and stomach. Lesser amounts of glycogen were present in vascular smooth muscle cells of arteries and Schwann cell cytoplasm of nerves (chordae equina). Additionally, brain tissue revealed periodic acid-Schiff (PAS)-positive material in vascular smooth muscle cells of a small arteriole and occasional PAS-positive material in Schwann cell cytoplasm.

Antibody responses. Individual patients' rhGAA titers during the treatment period are shown in figure 5. Sixteen of the 18 patients developed IgG antibodies to rhGAA. One patient was seropositive at baseline, suggesting preexisting cross-reactivity; and two patients remained seronegative throughout the study. Nine of the remaining patients seroconverted by week 4, another four patients seroconverted by week 8 , one patient seroconverted by week 12 , and one patient seroconverted at week 64 . One patient (Patient L), who developed high titers of IgG, tested positive for inhibitory antibodies at weeks 52 and 64 of treat- 


\begin{tabular}{|c|c|c|c|c|c|c|}
\hline \multirow{2}{*}{$\begin{array}{l}\text { Patient } \\
\mathrm{A}\end{array}$} & \multirow{2}{*}{$\begin{array}{c}\begin{array}{c}\text { Dose } \\
\text { group } \\
(\mathrm{mg} / \mathrm{kg})\end{array} \\
40\end{array}$} & \multicolumn{2}{|c|}{$\begin{array}{c}\text { GAA activity } \\
(\mathrm{nmol} / \mathrm{h} / \mathrm{g} \text { tissue })\end{array}$} & \multirow{2}{*}{$\begin{array}{c}\begin{array}{c}\text { Percentage of } \\
\text { increase in glycogen } \\
\text { content from } \\
\text { baseline to wk } 52\end{array} \\
64.3\end{array}$} & \multirow{2}{*}{$\begin{array}{c}\begin{array}{c}\text { Change in } \\
\text { glycogen } \\
\text { content* }\end{array} \\
\text { Increased }\end{array}$} & \multirow{2}{*}{$\begin{array}{c}\text { Motor } \\
\text { status at } \\
\text { wk } 52 \dagger\end{array}$} \\
\hline & & Baseline & BQL & & & \\
\hline & & Wk 52 & 140.9 & & & \\
\hline B & 20 & Baseline & 8.8 & 2.2 & Stable & Walking \\
\hline & & Wk 52 & 69.9 & & & \\
\hline $\mathrm{C}$ & 40 & Baseline & $\mathrm{BQL}$ & -26.4 & Decreased & Walking \\
\hline & & Wk 52 & 75.0 & & & \\
\hline D & 20 & Baseline & $\mathrm{BQL}$ & -38.0 & Decreased & No gains \\
\hline & & Wk 52 & 68.9 & & & \\
\hline $\mathrm{E}$ & 20 & Baseline & 8.5 & 49.6 & Increased & No gains \\
\hline & & Wk 52 & 138.8 & & & \\
\hline $\mathrm{F}$ & 40 & Baseline & BQL & -48.6 & Decreased & Walking \\
\hline & & Wk 52 & 74.0 & & & \\
\hline G & 40 & Baseline & $\mathrm{BQL}$ & -53.2 & Decreased & Walking \\
\hline & & Wk 52 & 144.8 & & & \\
\hline $\mathrm{H}$ & 20 & Baseline & 4.6 & -26.4 & Decreased & Walking \\
\hline & & Wk $67 \ddagger$ & 26.3 & & & \\
\hline I & 20 & Baseline & $\mathrm{BQL}$ & -19.3 & Decreased & Standing \\
\hline & & Wk 52 & 49.0 & & & \\
\hline J & 40 & Baseline & BQL & -77.5 & Decreased & Sitting \\
\hline & & Wk 52 & 1298.3 & & & \\
\hline $\mathrm{K}$ & 20 & Baseline & $\mathrm{BQL}$ & -49.7 & Decreased & Sitting \\
\hline & & Wk 52 & 67.0 & & & \\
\hline $\mathrm{L}$ & 40 & Baseline & $\mathrm{BQL}$ & ND & ND & Standing \\
\hline & & Wk 52 & $\mathrm{ND}$ & & & \\
\hline M & 20 & Baseline & $\mathrm{BQL}$ & -28.3 & Decreased & Standing \\
\hline & & Wk 52 & 152.7 & & & \\
\hline $\mathrm{N}$ & 40 & Baseline & $\mathrm{BQL}$ & -29.5 & Decreased & Walking \\
\hline & & Wk 52 & 133.3 & & & \\
\hline $\mathrm{O}$ & 20 & Baseline & $\mathrm{BQL}$ & -20.9 & Decreased & Walking \\
\hline & & Wk 52 & 70.4 & & & \\
\hline $\mathrm{P}$ & 40 & Baseline & $\mathrm{BQL}$ & -89.3 & Decreased & No gains \\
\hline & & Wk 52 & 558.8 & & & \\
\hline $\mathrm{Q}$ & 40 & Baseline & $\mathrm{BQL}$ & -4.5 & Stable & Sitting \\
\hline & & Wk 52 & 55.4 & & & \\
\hline $\mathrm{R}$ & 20 & Baseline & BQL & 11.5 & Stable & No gains \\
\hline & & Wk 52 & 185.8 & & & \\
\hline
\end{tabular}

* A change in glycogen content was designated as increased or decreased if the percentage of change from baseline was $>20 \%$. Patients with glycogen levels within $20 \%$ of their baseline values were designated as stable.

$\dagger$ Motor status was determined by assessment of motor milestones.

$\$$ Patient $\mathrm{H}$ underwent a skeletal muscle biopsy at week 67 because the patient was too ill to undergo the procedure at week 52

$\mathrm{BQL}=$ below quantifiable levels $(<3.3 \mathrm{nmol} / \mathrm{h} / \mathrm{g}$ tissue $) ; \mathrm{ND}=$ not determined.

ment, exhibiting $12.4 \%$ inhibition at week 52 and $23.2 \%$ inhibition at week 64 .

Dose effects. The proportions of patients who were alive, free of invasive ventilation, and showed improvements in left ventricular mass, growth, and motor develop- ment were similar in the $20-$ and $40-\mathrm{mg} / \mathrm{kg}$ dose groups. Although the clinical responses were similar in the two dose groups, skeletal muscle GAA activity increased more in the $40-\mathrm{mg} / \mathrm{kg}$ group (median $137 \mathrm{nmol} / \mathrm{h} / \mathrm{g}$ tissue) than in the $20-\mathrm{mg} / \mathrm{kg}$ group (median $70.1 \mathrm{nmol} / \mathrm{h} / \mathrm{g}$ tissue) at 


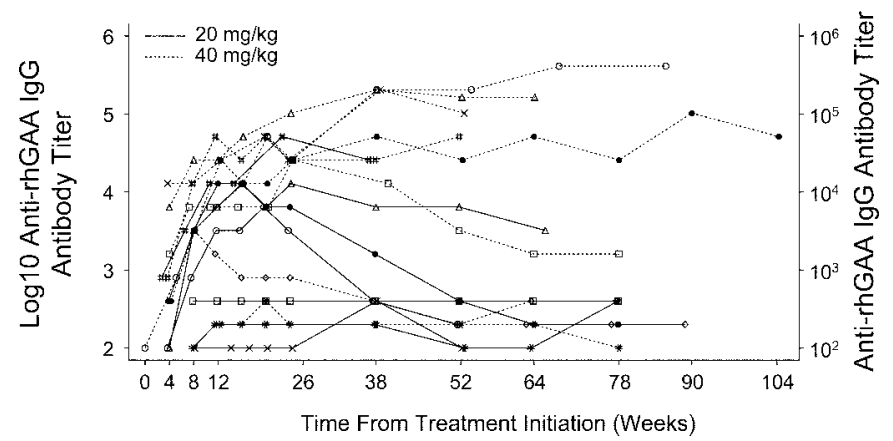

Figure 5. Anti-rhGAA IgG antibody titers over time. Note that data are displayed only for nonzero antibody titers (Patients $K$ and $N$ did not display detectable antibody titers at any time point).

week 52. Similarly, glycogen levels in skeletal muscle as measured by biochemical analysis also showed a trend for greater reductions in the $40-\mathrm{mg} / \mathrm{kg}$ group (median decrease $75.0 \%$ from baseline) as compared to the $20-\mathrm{mg} / \mathrm{kg}$ dose group (median decrease $45.2 \%$ from baseline). Similar numbers of patients in each dose group experienced IARs; however, the five patients in the $20-\mathrm{mg} / \mathrm{kg}$ dose group experienced a total of 41 IARs and the six patients in the $40-\mathrm{mg} / \mathrm{kg}$ dose group experienced a total of 123 IARs. Most of the IARs (69.5\%) were experienced by three patients who had recurrent reactions: one in the $20-\mathrm{mg} / \mathrm{kg}$ dose group and two in the $40-\mathrm{mg} / \mathrm{kg}$ dose group. Of the patients who experienced IARs, those in the $40-\mathrm{mg} / \mathrm{kg}$ group had more symptoms per infusion during which IARs occurred than those in the $20-\mathrm{mg} / \mathrm{kg}$ dose group; however, these events were generally similar in nature in the two dose groups.

Genotyping and CRIM status. Mutations in the GAA gene were analyzed in 15 patients (30 alleles). Eleven novel mutations were identified. Each of the 15 patients with GAA gene mutation data had a unique combination of GAA mutations; therefore, it was not possible to draw conclusions regarding the effect of specific GAA mutations on efficacy outcomes. The genotyping data will be presented in detail in a separate study (manuscript in preparation). Three of the 18 patients (Patients C, L, and R) were CRIM negative as determined by Western blot; the remaining 15 patients were CRIM positive.

Discussion. This study examined the safety and efficacy of IV rhGAA treatment at 20 or $40 \mathrm{mg} / \mathrm{kg}$ every other week for 52 weeks in 18 patients with severe infantile-onset Pompe disease. Safety data were analyzed for the duration of treatment (ranging from 52 to 106 weeks, depending on when the patient was enrolled). Our inclusion criteria were designed to select the most severe end of the phenotype spectrum of Pompe disease, both in degree of GAA deficiency ${ }^{2}$ and in the presence of cardiomyopathy. ${ }^{5}$ The clinical endpoints, survival (with and without invasive or any ventilation), left ventricular mass decrease, and motor development, are in accord with the known natural history of the disease ${ }^{2,6} \mathrm{~A}$ previous clinical trial with another form of rhGAA showed that patients who started treatment before the occurrence of extensive muscle damage had better mo- tor outcomes than patients who began treatment at more advanced stages of disease progression. ${ }^{11}$ Therefore, we enrolled patients who were aged 6 months or younger at the onset of treatment.

Pompe disease is progressively debilitating and often fatal. For patients with the most aggressive form of the disease, such as those enrolled in this study, death from cardiac and/or respiratory failure typically occurs before 12 months of age..$^{1,2,6}$ rhGAA treatment markedly extended survival and improved respiratory performance in these patients. Fifteen of the 18 patients reached the age of 18 months at the end of the study period. The three patients who were right-censored from the survival analysis were all alive at the end of the study (at ages 15.9, 17.9, and 14.4 months). In contrast, only one of 61 historical control patients survived to the age of 18 months. Six of the 18 patients in the study required some type of ventilator support (three invasive, three noninvasive) at 18 months of age. Our comparisons of invasive-ventilator-free or ventilator-free survival in treated patients to overall survival in the control group of untreated patients represent a conservative approach; large treatment vs control differences in these endpoints were confirmed through numerous sensitivity analyses (data not shown). In addition, a Cox proportional hazard analysis demonstrated that rhGAA treatment reduced the risk of death by $99 \%$, reduced the risk of death or invasive ventilation by $92 \%$, and reduced the risk of death or any type of ventilation by $88 \%$, as compared to the untreated historical control group (all significant with $p<0.001$ ).

Echocardiographic measurements showed that rhGAA treatment markedly improved cardiomyopathy (i.e., left ventricular mass reduction) in all patients with 52 -week follow-up data $(n=15)$. This response to treatment is similar to what has been observed in previous clinical trials with rhGAA enzyme replacement therapy $(\mathrm{ERT})^{7-11}$ and suggest that rhGAA treatment effectively reduces glycogen accumulation in human cardiac tissue. In contrast, cardiomyopathy and massive cardiomegaly lead to fatal cardiorespiratory failure in a majority of untreated patients., ${ }^{2,6}$. Given that cardiorespiratory failure is one of the primary causes of death in patients with infantile-onset Pompe disease, ${ }^{1,2,6}$ the improvement in cardiomyopathy observed in response to rhGAA treatment almost certainly contributes to the prolonged survival.

Infantile-onset Pompe disease is characterized by profound muscle weakness, which generally involves substantial hypotonia and flaccidity, and is often referred to as floppy baby syndrome. ${ }^{1}$ Patients treated with rhGAA exhibited motor development that progressed well beyond the point at which it becomes arrested in untreated patients. ${ }^{2,6}$ In striking contrast to the nonattainment or loss of motor skills in patients in the untreated historical control group, 13 of the 18 treated patients acquired substantial motor and functional skills as assessed by the AIMS and Pompe PEDI tests. These skills, including independent ambulation, represent a much more advanced 
stage of motor development than what is typically observed in untreated patients. ${ }^{2,6}$ The remaining five patients exhibited few motor and functional gains over the 52-week treatment period. However, all five of these patients had very little, if any, residual motor function at baseline and required some type of ventilation during the 52 -week treatment period, which indicates an advanced stage of muscle involvement, including the respiratory muscles. Overall, the 18 patients in this study made more motor gains than patients in previous clinical trials with rhGAA ERT, ${ }^{7-11}$ possibly because ERT was initiated at such an early age (and therefore at an earlier stage of disease progression) in this study.

rhGAA treatment greatly increased skeletal muscle GAA activity in all patients, but to a greater degree in patients receiving $40 \mathrm{mg} / \mathrm{kg}$ rhGAA than in patients receiving $20 \mathrm{mg} / \mathrm{kg}$ rhGAA. Fourteen of the 17 patients who had glycogen levels evaluated at week 52 exhibited stable or decreased muscle glycogen content as compared to baseline, as determined biochemically. Twelve of these 14 patients made motor gains during the 52-week treatment period. None of the three patients whose muscle glycogen content increased during treatment showed any meaningful motor improvements. These findings suggest an association between the stabilization of or reduction in skeletal muscle glycogen content and improvements in motor function in most, but not all patients. These results are consistent with previous findings, showing that increases in GAA activity levels in a muscle group do not always correlate with glycogen clearance in that muscle and glycogen reduction in a given muscle cannot be generalized to other muscle groups. ${ }^{11}$

No patients discontinued the rhGAA treatment due to unmanageable infusion-associated reactions, similar to what has been observed in previous clinical trials with another form of rhGAA ERT. ${ }^{7-11}$ IARs experienced were managed with rate reductions, interruptions of rhGAA infusions, or symptomatic treatment, such as antihistaminics, acetaminophen, or glucocorticosteroids.

Similar numbers of patients in each dose group experienced AEs and IARs, although more IARs $(75.0 \%)$ were experienced by the group of patients assigned to the $40-\mathrm{mg} / \mathrm{kg}$ dose than by those assigned to the $20-\mathrm{mg} / \mathrm{kg}$ dose of rhGAA. Patients receiving the $40-\mathrm{mg} / \mathrm{kg}$ dose of rhGAA tended to develop a more robust antibody response, experienced more IARs, and, when experiencing IARs, had more symptoms than the patients in the $20-\mathrm{mg} / \mathrm{kg}$ dose group. The timing of the first occurrence of IARs did not closely coincide with the timing of seroconversion or the magnitude of anti-rhGAA IgG titers. There was no clear advantage of the higher dose on efficacy.

Three of the 18 patients in this study were CRIM negative (Patients C, L, and R). By week 52, Patient $\mathrm{C}$ had learned to walk, Patient $\mathrm{L}$ had learned to stand, and Patient $R$ had made no motor gains. In a previous study of three patients with infantile-onset Pompe disease, two patients who gained and then lost motor skills were CRIM negative, whereas the third, CRIM-positive patient in that study steadily gained motor milestones. ${ }^{7}$ However, a study of four patients with infantile-onset Pompe disease (one of whom was CRIM negative) who were treated with rhGAA derived from rabbit milk did not find an association between CRIM status and motor development. ${ }^{23}$ Although the total number of patients studied remains small, increasing evidence suggests that CRIM-negative patients are more likely to develop a higher, more sustained immunologic response against rhGAA than CRIM-positive patients and potentially a more limited duration of clinical benefit after rhGAA administration. In the current study, one of the 18 patients developed antibodies that inhibit in vitro rhGAA enzyme activity, which may represent a mechanism of antibody interference in humans. The presence of inhibitory antibodies has previously been observed in patients who have received ERT to treat other lysosomal storage diseases, such as Gaucher and Fabry disease, although it is an uncommon occurrence. ${ }^{24-27}$ Clearly, these observations cannot be considered conclusive, as the total number of CRIM-negative patients studied to date is quite limited. In addition to CRIM status and the development of inhibitory antibodies, it is important to note that other factors, such as rate of disease progression and residual functional status at onset of rhGAA treatment, may affect clinical outcomes in patients with infantile-onset Pompe disease. Thus, long-term follow-up is warranted in order to provide a better understanding of the response to ERT.

This study includes the largest cohort of patients with Pompe disease treated with ERT to date. These findings show that rhGAA treatment clearly prolongs ventilator-free survival and overall survival in patients with infantile-onset Pompe disease as compared to an untreated historical control population. Furthermore, this study demonstrates that initiation of ERT prior to 6 months of age, which could be facilitated by newborn screening, shows great promise to reduce the mortality and disability associated with this devastating disorder.

\section{Acknowledgment}

The authors thank the patients who participated in this clinical study and their families. They also thank the study coordinators, nurses, and technical staff at the various treatment centers. The expertise of Katherine Cox, Jennifer Hunt, Edward Kaye, MD, Nancy Mulrow, MD, Dominique Nijkamp, Tara O’Meara, Khazal Paradis, MD, and Nancy Silliman, $\mathrm{PhD}$ (from Genzyme Corporation) also supported this study.

\section{References}

1. Hirschhorn R, Reuser AJ. Glycogen storage disease type II: acid $\alpha$-glucosidase (acid maltase) deficiency. In: Scriver CR, Beaudet AL, Sly WS, et al., eds. The metabolic and molecular bases of inherited disease. New York: McGraw-Hill, 2001:3389-3420.

2. van den Hout HMP, Hop W, van Diggelen OP, et al. The natural course of infantile Pompe's disease: 20 original cases compared with 133 cases from the literature. Pediatrics 2003;112:332-340.

3. Kishnani PS, Steiner RD, Bali D, et al. Pompe disease diagnosis and management guideline. Genet Med 2006;8:267-288.

4. Chen YT, Amalfitano A. Towards a molecular therapy for glycogen storage disease type II (Pompe disease). Mol Med Today 2000;6:245251 
5. Slonim AE, Bulone L, Ritz S, Goldberg T, Chen A, Martiniuk F. Identification of two subtypes of infantile acid maltase deficiency. J Pediatr 2000;137:283-285.

6. Kishnani PS, Hwu, W-L, Mandel H, et al. A retrospective, multinational, multicenter study on the natural history of infantile-onset Pompe disease. J Pediatr 2006;148:671-676.

7. Amalfitano A, Bengur AR, Morse RP, et al. Recombinant human acid $\alpha$-glucosidase enzyme therapy for infantile glycogen storage disease type II: results of a phase I/II clinical trial. Genet Med 2001;3:132-138.

8. Van den Hout JM, Reuser AJ, de Klerk JB, Arts WF, Smeitink JA, Van der Ploeg AT. Enzyme therapy for Pompe disease with recombinant human alpha-glucosidase from rabbit milk. J Inherit Metab Dis 2001; 24:266-274.

9. Van den Hout JMP, Kamphoven JHJ, Winkel LPF, et al. Long-term intravenous treatment of Pompe's disease with recombinant human alpha glucosidase from milk. Pediatrics [serial online] 2004;113:448457. Available at http://pediatrics.aappublications.org. Accessed August $1,2006$.

10. Klinge L, Straub V, Neudorf U, et al. Safety and efficacy of recombinant acid alpha-glucosidase (rhGAA) in patients with classical infantile Pompe disease: results of a phase II clinical trial. Neuromuscul Disord 2005;15:24-31.

11. Kishnani PS, Nicolino M, Voit T, et al. Results from a phase II trial of Chinese hamster ovary cell-derived recombinant human acid $\alpha$-glucosidase in infantile-onset Pompe disease. J Pediatr 2006;149:89-97.

12. Piper MC, Darrah J. Motor assessment of the developing infant. Philadelphia: WB Saunders, 1994.

13. Feldman AB, Haley SM, Coryell J. Concurrent and construct validity of the Pediatric Evaluation of Disability Inventory. Phys Ther 1990;70: 602-610.

14. Haley SM, Fragala MA, Aseltine R, Ni P, Skriner AM. Development of a disease-specific disability instrument for Pompe disease. Pediatr Rehabil 2003;6:77-84.

15. Haley SM, Fragala-Pinkham MA, Ni PS, Skriner AM, Kaye EM. Pediatric physical functioning reference curves. Pediatr Neurol 2004;31: 333-341.
16. Bayley N. Bayley Scales of Infant Development, 2nd ed. New York: Harcourt Brace, 1993.

17. Kaplan EL, Meier P. Nonparametric estimation from incomplete observations. J Am Stat Soc 1958;53:457-481.

18. Reuser AJ, Koster JF, Hoogeveen A, Galjaard H. Biochemical, immunological, and cell genetic studies in glycogenosis type II. Am J Hum Genet 1978;30:132-143.

19. Cox DR. Regression models and life tables (with discussion). J R Statist Soc Ser 1972;B34:187-220.

20. Wandt B, Bojo L, Tolagen K, Wranne B. Echocardiographic assessment of ejection fraction in left ventricular hypertrophy. Heart 1999;82:192-198.

21. Kuczmarski RJ, Ogden LGrummer-Strawn LM, et al. CDC growth charts: United States. Advance data from vital and health statistics; no. 314. Hyattsville, MD: National Center for Health Statistics, 2000 .

22. Kamphoven JH, de Ruiter MM, Winkel LP, et al. Hearing loss in infantile Pompe's disease and determination of underlying pathology in the knockout mouse. Neurobiol Dis 2004;16:14-20.

23. Van den Hout H, Reuser AJ, Vulto AG, Loonen MC, Cromme-Dijkhuis A, Van der Ploeg AT. Recombinant human alpha-glucosidase from rabbit milk in Pompe patients. Lancet 2000;356:397-398.

24. Brady RO, Murray GJ, Oliver KL, Leitman SF, Fleisher TA, Barton NW. Management of neutralizing antibody to ceredase in a patient with type 3 Gaucher disease. Pediatrics 1997;100:E11.

25. Ponce E, Moskovitz J, Grabowski GA. Enzyme therapy in Gaucher disease type 1: effect of neutralizing antibodies to acid b-glucosidase. Blood 1997;90:43-48.

26. Rosenberg M, Kingma W, Fitzpatrick MA, Richards SM. Immunosurveillance of alglucerase enzyme therapy for Gaucher patients: induction of humoral tolerance in seroconverted patients after repeat administration. Blood 1999;93:2081-2088.

27. Zhao H, Bailey LA, Grabowski GA. Enzyme therapy of Gaucher disease: clinical and biochemical changes during production of and tolerization for neutralizing antibodies. Blood Cells Mol Dis 2003;30: 90-96.

\section{P WWW.NEUROLOGY.ORG OFFERS IMPORTANT INFORMATION TO PATIENTS AND THEIR FAMILIES}

The Neurology Patient Page provides:

- a critical review of ground-breaking discoveries in neurologic research that are written especially for patients and their families

— up-to-date patient information about many neurologic diseases

— links to additional information resources for neurologic patients.

All Neurology Patient Page articles can be easily downloaded and printed, and may be reproduced to distribute for educational purposes. Click on the Patient Page icon on the home page (www.neurology.org) for a complete index of Patient Pages. 


\section{Neurology}

\section{Recombinant human acid $\alpha$-glucosidase: Major clinical benefits in infantile-onset Pompe disease}

P. S. Kishnani, D. Corzo, M. Nicolino, et al.

Neurology 2007;68;99-109 Published Online before print December 6, 2006

DOI 10.1212/01.wnl.0000251268.41188.04

\section{This information is current as of December 6, 2006}

\section{Updated Information \& Services}

References

Citations

Subspecialty Collections

Permissions \& Licensing

Reprints including high resolution figures, can be found at: http://n.neurology.org/content/68/2/99.full

This article cites 23 articles, 4 of which you can access for free at: http://n.neurology.org/content/68/2/99.full\#ref-list-1

This article has been cited by 28 HighWire-hosted articles: http://n.neurology.org/content/68/2/99.full\#\#otherarticles

This article, along with others on similar topics, appears in the following collection(s):

\section{All Clinical trials}

http://n.neurology.org/cgi/collection/all_clinical_trials

Clinical trials Observational study (Cohort, Case control)

http://n.neurology.org/cgi/collection/clinical_trials_observational_study _cohort_case_control

Glycogenoses

http://n.neurology.org/cgi/collection/glycogenoses

Muscle disease

http://n.neurology.org/cgi/collection/muscle_disease

Information about reproducing this article in parts (figures,tables) or in its entirety can be found online at:

http://www.neurology.org/about/about_the_journal\#permissions

Information about ordering reprints can be found online:

http://n.neurology.org/subscribers/advertise

Neurology ${ }^{\circledR}$ is the official journal of the American Academy of Neurology. Published continuously since 1951, it is now a weekly with 48 issues per year. Copyright . All rights reserved. Print ISSN: 0028-3878. Online ISSN: 1526-632X.

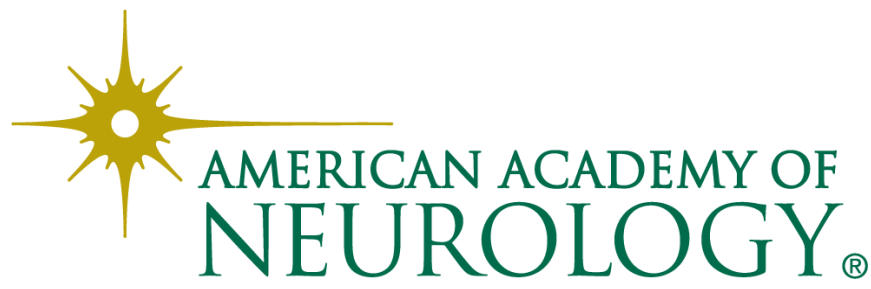

